\title{
Multiple Intelligences-Based Homework and EFL Students' Vocabulary Learning
}

\author{
Le Thi Tuyet Hanh ${ }^{1,2} \&$ Tran Ba Tien ${ }^{2}$ \\ ${ }^{1}$ Hue University of Foreign Languages, Vietnam \\ ${ }^{2}$ Department of Foreign Languages, Vinh University, Vietnam \\ Correspondence: Le Thi Tuyet Hanh, Foreign Languages Department, Vinh University, Vinh City, Nghe an, \\ Vietnam. E-mail: lehanh@vinhuni.edu.vn or tientb@vinhuni.edu.vn
}

Received: June 24, 2017 Accepted: July 28, 2017 Online Published: September 25, 2017

doi:10.5539/ijel.v7n6p73 URL: http://doi.org/10.5539/ijel.v7n6p73

\begin{abstract}
This paper investigates the effects of Multiple Intelligences-based homework on EFL students' vocabulary learning at a university in Vietnam. Based on the Multiple Intelligences (MI) Theory framework and Action Research approach, the homework instructions were adapted according to different types of intelligences. After four weeks of practice, it was found that students made use of different strategies to learn new words. They also showed creativity and a greater enthusiasm toward vocabulary learning.
\end{abstract}

Keywords: vocabulary learning, vocabulary learning strategies, Multiple Intelligences Theory, MI based homework

\section{Introduction}

Vocabulary learning has recently attracted much attention from researchers all over the world because of its important role in language learning. It is thought that "without grammar, very little can be conveyed, without vocabulary, nothing can be conveyed" (Wilkins, 1990, p. 72).However, a recent survey at Vinh University in Vietnam showed that most of EFL learners cannot reach the minimum or threshold level of a "core vocabulary" of 2000 high frequency words needed to function in most situations. Most researchers nowadays recommend a basic vocabulary of at least 3000 word families, while for more specialized needs, a working vocabulary of over 5000 word families is probably desirable (Thornburry, 2002). In order to have a better understanding of the situation, a pre-interview was conducted among 401 university students by the researchers and it was found that learners' autonomy and their strategies of learning vocabulary emerge as two problems worth being taken into account: the rote repetition and word lists seem to be two ways most exploited by students in learning vocabulary; and most of the students reported that their vocabulary learning strategies were mostly influenced by their teachers and friends. They also claimed that these short-lasting desires to learn new words were a separate subject because they found this kind of learning boring. It was evident that the teaching strategies needed to be changed to encourage students to enrich their vocabulary stock.

One of the theories that have recently emerged in the educational science is the Multiple Intelligences Theory (MI) initiated by Gardner (1983). He identifies eight central intelligences:

- Linguistic intelligence: capacity to use words effectively, orally or in writing;

- Logical-mathematical intelligence: capacity to use numbers effectively and to reason well;

- Visual-spatial intelligence: ability of using mental imagery for discerning orientation in space;

- Bodily-kinesthetic intelligence: capacity of using physical body movements to express emotion and ideas;

- Musical intelligence: capacity to perceive, transform, and express musical forms;

- Interpersonal intelligence: ability to perceive and make distinction in the moods, intentions, motivations and feelings of other people;

- Intrapersonal intelligence: self-knowledge and ability to act adaptively on the basis of that knowledge;

- Naturalist intelligence: expertise in the recognition and classification of the numerous species- - the flora and the fauna - of an individual environment. Gardner explains about the possible intelligence: "existential 
intelligence", which he suggests as the ninth one (Gardner, 1999).

A body of research has been conducted to gain an insight into the application of the MI theory in language acquisition, especially in foreign and second language settings (Richards \& Rogers, 2001; Armstrong, 2009; Christison, 2005). The findings all affirmed that MI possesses potential to be used in the teaching and learning of languages in many ways: it provides multiple routes to learning (Armstrong, 2009); various teaching strategies and approaches (Richard \& Rogers, 2001). Especially, MI based instructions motivate learners by spurring multiple ways of ascribing meaning to vocabulary being acquired (Richard \& Rogers, 2001). Based on the current situation and the literature review about MI theory application in the classroom, we decided to assign MI homework to students in our classes to see if the MI approach has any positive impact on students' change of strategies in learning English vocabulary.

Action Research (AR) was employed as it is a form of procedural practical improvements in which teachers aim to make positive changes in their professional context (McKernan, 2008). As a result, teachers can improve their teaching practice since they are the ones who best understand their own challenges as well as students' learning problems. The research, inspired from MI theory, was conducted though four steps adapted from Kemmis \& McTaggart (1988): planning, action, observation and reflection.

\section{Methodology}

\subsection{Research Context}

The research was conducted over a four-week period in an English major reading class at Vinh University. Thirty five students who participated in this study were in their third semester. The text book was Q-Skills reading and writing 3, targeting at the B2 level in the CEFR. Each of the ten units in this course book consists of a vocabulary section, two reading texts, followed by different types of reading comprehension questions. Even though the text book was used as the official one in the foreign languages department, the lesson plan depends on the individual teachers. Therefore, there exists a lot of room for teachers to develop their creativity during teaching time.

\subsection{Procedure}

To begin with, the researcher explained to her students about the requirements for making their vocabulary learning better. The MI theory was also introduced in order to inform students the purpose of differentiating the homework instructions as well as to make them aware of their potentials. Accordingly, each student was required to do homework about the word they have learned after each reading unit. Each week, they were asked to complete the task according to each type of intelligence. In the scope of the study, four types of MI-based homework were involved: linguistic, visual, intrapersonal, and interpersonal.

Students' homework, teacher's observation and interview about students' perception were used as data collection instruments. The researcher performed a four-step process as follows:

1) The teacher asked students to describe the strategies they used to learn new words and the words they have learned after each unit in a specific style.

2) Students sent their homework to the teacher by email according to a fixed deadline.

3) The teacher collected the homework and arrange a peer review the following week

4) The best homework was awarded to encourage students' participation.

When the first unit was finished, the teacher asked students to write the diaries in the linguistic style, which she thought the most familiar way for students to adapt in their writing. The next four weeks would be followed by visual, intrapersonal, and interpersonal styles.

After a week, students were asked to send their diary homework though email to the teacher, three days after the lesson. If any students did not take their homework as a serious task, their work would be sent back to be rewritten. The teacher provided comments about their homework. After three days, these diaries were sent to different students in the class through email. The effectiveness of peer learning has been justified in many studies (Topping, 1996; Ohta, 2001). That was why this peer review helped students to learn from each other and gave scores for the writing they had received. The criteria included the number of words included in the writing, the originality, and the level of required skill (writing, drawing, etc.)

The best homework was posted on the class Facebook page for other students to read, and the author of this work was awarded 0.5 points for their midterm tests. Besides, all the assignments were considered the criteria for students' attitude assessment, which accounted for $10 \%$ of the total grades. 
The data collection instruments included observation, students' diaries, and interviews.

\section{Findings and Discussion}

\subsection{Student's Homework}

Most students showed a positive attitude to the task. For the first week, most students sent the diaries on time and some even created a story line with all the new words they learn in the unit. However, some students seemed to neglect the task by just only writing some short lines in their diaries. One student showed her disagreement with the task by writing as follow:

Today I really didn't want to get up, but I had to do. It is raining cats and dogs. I went to school at 8.15 a.m to learn reading subject. I thought about journal and I hate this thing. Rather, my reading teacher gave us a lot of homework. Although I am lazy, I will try to complete it. I hope I study better.

To fix the problem, the teacher had to repeat the rule to all students and added that the homework would account for $50 \%$ of midterm test score. The next homework required students to present their work in the form of pictures. All students took part in this part in seriously. Some students had difficulties with their painting skill on certain computer software, so they drew the picture and took the photo of it to send to the teacher. The best picture was printed out and brought to the class. Most of the students used new words in a mind map or "spider diagram" as some called it.

The third assignment was for students to choose the way they presented their new words. The results were amazing. The topic was about sports. Many students chose to do the homework in traditional way, by summarizing new words in a paragraph, for instance; others liked to draw mind maps. Some students even made up a story between Tom and Jerry to include all the new words, here is an extract:

On the way to go home, two students, Tom and Jerry are chatting...

...Then they continue walking home. They pass a football pitch* and watch a match for a while. All of the players are brilliant. However the Red team beat the Green team by 3 goals to 1. After that, Tom and Jerry keep walking. They also see a tennis court and a long running track. Some people are playing handball, some are doing karate or going motorbike racing. All look great. These things are attractive to them. They make up their mind to be excellent athletes one day.

Two young students chat so passionately that they forget to bring their parents a tennis racket, a golf club, a saddle and two pairs of ice skates. Poor Tom and Jerry have to come back to finish their mission. They should have a word with their mom and dad to make it clear. Otherwise, their parents can't stand their sons coming home too late.

*all the bold words are new words in the unit

The fourth homework related to the group work about health. This time, students were assigned to 6 groups and each group consisted of 5 people. They were asked to present their new words learnt in the unit in any ways they come to agree among group members. Then, the result was submitted to the teacher. The score was given to all the members of group after they had talked about how to come to this end. Surprisingly, one group chose to present their new words though group games. They designed a game for all the members to take part in. The game was simple. Each member had to write all the new words on the board in 5 minutes, who had the most words right was the winner and had one more mark to the group mark from the teacher. Of course they had negotiated with the teacher before the game happened. A period of two hours was needed for the presentation of all groups. A student shared that she had never thought that she could memorize 20 difficult words about health and medicine in a day, but thanks to the game, she then recalled such words easily.

\subsection{The Interviews}

The online interview aimed to find out students' perception of the MI homework. This Facebook interview was designed because all of the students have Facebook accounts, so it was convenient for the teacher as well as the students to ask and answer the questions whenever they could. The interview was conducted through Facebook inbox. The eight questions were inboxed to students, if there was any ambiguity from any answer, the teacher would type the question to that students to make it clear.

The data showed that all the students thought that learning vocabulary is very important in language learning, but they did not have any planned practice. As a result, $80 \%$ appreciated the implementation of MI based homework; meanwhile the rest claimed that strategies consumed quite a lot of time for them.

The study also revealed that many students showed a preference for creating the homework by their own ways in 
the linguistic style. It might be in the form of a paragraph, a story, a poem. However, about $10 \%$ of the respondents still favored the traditional strategies to learn new words, such as teacher guidance; note taking and rote memorization). Interestingly, most of the students found the MI based homework useful to the extent that they can know more about different ways to learn new words and find out what style is the most efficient for them.

\subsection{Reflection on MI based Homework}

There is a strong evidence that students' lack of practices of using new words prevented them from widening their vocabulary size. Therefore, this compulsory homework appeared as a way to force student to get familiar to different approach to new words. Moreover, the MI homework helped students to recognize their potentials and discover the most effective way for them to memorize new words. Students also had chance to learn from and be learnt by their classmates. The MI based homework not only helped students to diversify their ways to learn new words, but also assist them to practise using new words in different ways. Furthermore, the learning process became more student-centered. However, these types of tasks might create a certain burden for the teacher because she had to glance on all the work every week. This might also result in time consuming and difficulties in classroom management if the class size is big.

\subsection{Reflection on Students' Engagement and Motivation}

The first week did not witness the enthusiastic involvement of the participants because they did not use to officially learning new words and they found it a bit boring. However, this feeling was soon replaced by a positive attitude thanks to the variety of homework instructions and required strategies. More than $96 \%$ of students reported that the differentiated requirement created in them a somewhat excitement to learn new words. The fact of learning lexical items was not as boring as before. The learning environment became more enjoyable. More importantly, there were always peers and best peers to confer when they needed help. Moreover, the time consuming of the task give the chance to think about the ways they develop the tasks and help them keep the words in mind longer.

\section{Pedagogical Implications}

This research was the first step to introduce, in a compulsory way, the strategies to learn English vocabulary in light of MI Theory. This theory can be used as a framework for designing vocabulary teaching activities to tap different minds in different ways. When there are various approaches and methods for obtaining educational aims and the learners find the content containing interesting activities, they learn it and experience less anxiety in solving learning problems. "MI framework helps the learners gain better self-awareness about learning abilities in different intelligence areas" (Soleimani et al., 2012, p.50). Even though there has not been a separate subject to teach vocabulary, this approach can be integrated during reading classes, even in writing classes.

Another suggestion is provided for the researchers who are interested in this field. It will be effective to apply MI theory in designing syllabus and developing educational curriculums whereupon EFL learners can satisfy themselves in language learning, including vocabulary learning, and they can learn better and improve their autonomy.

\section{Conclusion}

This AR calls for a continued cycle to make students get familiar to the MI strategies to acquire new words. Also, the need for clearer explanations, more various methods and more follow-up activities should be investigated further.The researcher plans to continue with the AR investigation by offering students their choice in styles to do their homework. This MI instruction will be applied to the writing class next semester. Besides, the research intended to implement some quantitative approach to see if there is any correlation between MI based homework and students' word retention. This action research aimed to enrich learners' vocabulary learning strategies and their attitude toward this learning. After four weeks of implementation, it was found that MI based homework helped students to vary their ways to learn lexical items more effectively. The finding also showed that students' attitude toward vocabulary learning changed and the learning environment became more enjoyable. Moreover, this AR helped teacher to reflect on their own teaching and developed it for a better application of the Theory.

Although the findings were reported from only four weeks of practice, it is significant to the extent that it provided a pre-view of teaching effectiveness in learning English vocabulary. Further research is needed to gain an in-depth understanding of this relatively new research area in Vietnam. 


\section{References}

Armstrong, T. (2009). When the cultures connect: Multiple Intelligences Theory as a successful American support to other countries. Multiple Intelligences around the world. Jossey-Bass, USA.

Christison, M. A. (2005). Multiple Intelligences and language learning.A guidebook of theory, activities, inventories, and resources. San Fransisco: Alta Books.

Gardner, H. (1983). Frames of Mind: the theory of multiple intelligences. Basic Books.

Kemmis, S., \& MacTaggart, R. (1988). The action research planner (3rd ed.). Geelong: Deakin University Press.

McKeman, J. (2008). The lexical approach: the state of ELT and a way forward. Boston: Heinle.

Ohta, A. S. (2001). Peer interactive tasks and assisted performance in classroom language learning. In A. S. Ohta (Ed.), Second language acquisition processes in the classroom: learning Japanese (pp. 77-128). Mahwah, NJ: Lawrence Erlbaum.

Richard, J., \& Rogers, T. (2001). Approaches and methods in language learning (2nd ed.). Cambridge: Cambridge University Press. https://doi.org/10.1017/CBO9780511667305

Soleimani, H. et al. (2012). The effect of instruction based on multiple intelligences theory on the attitude and learning of general English. English Language Journal, 5(9), 45-53. https://doi.org/10.5539/elt.v5n9p45

Thornbury, S. (2002). How to teach vocabulary. Pearson: Longman.

Topping, K. (1996). The Effectiveness of Peer Tutoring in Further and Higher Education: A Typology and review of the literature. Higher Education, 32(3), 321-345.

Wilkins, A. D. (1972). Linguistics in Language Teaching. Cambridge, MA: MIT Press.

\section{Copyrights}

Copyright for this article is retained by the author(s), with first publication rights granted to the journal.

This is an open-access article distributed under the terms and conditions of the Creative Commons Attribution license (http://creativecommons.org/licenses/by/4.0/). 